\title{
International Business Cycles With Endogenous Incomplete Markets
}

\author{
PATRICK J. KEHOE \\ Federal Reserve Bank of Minneapolis, \\ University of Minnesota, \\ and National Bureau of Economic Research \\ and \\ FABRIZIO PERRI \\ New York University \\ and Federal Reserve Bank of Minneapolis
}

JEL numbers: F41, F32, F21

Key words: credit constraints, debt constraints

Backus, Kehoe and Kydland (1992), Baxter and Crucini (1995) and Stockman and Tesar (1995) find two major discrepancies between standard international business cycle models with complete markets and the data: In the models, cross-country correlations are much higher for consumption than for output, while in the data the opposite is true; and crosscountry correlations of employment and investment are negative, while in the data they are positive. This paper introduces a friction into a standard model that helps resolve these anomalies. The friction is that international loans are imperfectly enforceable; any country can renege on its debts and suffer the consequences for future borrowing. To solve for equilibrium in this economy with endogenous incomplete markets, the methods of Marcet and Marimon (1999) are extended. Incorporating the friction helps resolve the anomalies more than does exogenously restricting the assets that can be traded.

\section{Corresponding author:}

Patrick J. Kehoe

Research Department

Federal Reserve Bank of Minneapolis

90 Hennepin Avenue

Minneapolis, MN 55480-0291 
Some quantitative properties of standard international business cycle models with complete markets are at odds with the data. (See, for example, Backus, Kehoe and Kydland (1992), Baxter and Crucini (1995) and Stockman and Tesar (1995).) Primarily, the cross-country correlations of consumption in standard models are much higher than those for output, while in the data the opposite is true. And in these models, both employment and investment in different countries comove negatively, while in the data these variables comove positively. Since these two discrepancies are robust to changes in both parameter values and the model structure, Backus, Kehoe and Kydland (1993) call them anomalies. One possible explanation for these anomalies, which has been stressed in the literature, is that standard models assume perfectly functioning international credit markets, while actual credit markets may work far from perfectly.

This paper introduces a friction into international credit markets to attempt to resolve the quantitative anomalies of business cycle models. The friction is that international loans are feasible only to the extent to which they can be enforced by the threat of exclusion from future intertemporal and interstate trade. (Here, we follow the literature on international debt, such as the studies of Eaton and Gersovitz (1981) and Manuelli (1986) and those surveyed by Eaton and Fernandez (1995) as well as the literature on debt-constrained asset markets, particularly the work of Kehoe and Levine (1993, forthcoming), Kocherlakota (1996), Ligon, Thomas and Worrall (1997), Alvarez and Jermann (2000) and Attanasio and Ríos-Rull (2000).) This friction captures in a simple way the difficulties of enforcing contracts between sovereign nations that involve large transfers of resources which are backed only by promises to repay later. Throughout, we focus on the difficulties of enforcing contracts between agents in different sovereign nations when sovereign governments can abrogate contracts; we abstract 
completely from the difficulties of enforcing contracts between agents within a country.

We find that including these enforcement difficulties in business cycle models does help resolve the anomalies. Briefly, we find that compared to the properties of a complete markets model, an economy with enforcement friction reduces the gap between the cross-country correlation of consumption and that of output and makes employment and investment in the two countries comove positively instead of negatively. The primary remaining conflict with the data is another type of discrepancy: in the model the correlation between net exports and output is positive instead of negative.

The model we study here is a standard international business cycle model modified to incorporate the credit market friction. The model has two countries, and the business cycle fluctuations are driven by country-specific productivity shocks. We follow the debtconstrained asset market literature and study a planning problem which includes, in addition to resource constraints, enforcement constraints which require that in each period and state, allocations can be enforced only if their value is greater than it would be if the country were excluded from all further intertemporal and interstate trade. This constrained planning problem has an infinite number of enforcement constraints with potentially complicated binding patterns.

To solve the constrained planning problem, we extend the recursive contract approach of Marcet and Marimon (1999). The key to this approach is to define as part of the state the current relative weight of one of the two countries from the planning problem. This relative weight is the original planning weight plus the sum of the history of all multipliers on the enforcement constraints up to that period for one country relative to the analogous sum for the other country. When the state of the world economy is enlarged to include this relative 
weight, the solution can be summarized by stationary decision rules.

The allocations from this constrained planning problem can be interpreted in at least two ways. Kehoe and Levine (1993) and Alvarez and Jermann (2000) interpret them as competitive equilibria in which the enforcement constraints are part of the private agent budget sets. We prefer to interpret the allocations as do Chari and Kehoe (1990, 1993), Kocherlakota (1996) and authors of some related work in the international debt literature: as equilibrium outcomes of a dynamic game. In this game, private agents solve standard competitive equilibrium problems, while the government of each country can choose to prevent its citizens from repaying their outstanding international debts and instead tax the income from capital. In a separate appendix (available upon request), we show that the allocations that solve the constrained planning problem can be supported as equilibria of this game only if they satisfy these enforcement constraints.

The theoretical implications of limited enforcement constraints have been studied before, but mostly in a pure exchange, closed economy setting. The papers by Kehoe and Levine (1993), Kocherlakota (1996) and Alvarez and Jermann (2000) study such constraints for simple pure exchange, closed economies, with the first two papers concentrating on quantity effects and the third on price effects. Ligon, Thomas and Worrall $(1997,2000)$ use simple quantitative economies to study insurance arrangements in villages in India, while Alvarez and Jermann (1998) study the quantitative implications of enforcement constraints for asset prices. Other applications include the work of Attanasio and Ríos-Rull (2000), who show that adding compulsory insurance in an economy with enforcement problems can interfere with the functioning of private markets. All of these papers study pure exchange economies except for that of Ligon, Thomas and Worrall (2000), which allows for storage. Our paper extends 
this analysis to a full-blown international business cycle model with standard neoclassical production functions and plausible parameter values.

A few papers - for example, those of Baxter and Crucini (1995), Kollmann (1996) and Heathcote and Perri (2000) - have investigated the quantitative impact of friction in international financial markets on the properties of international business cycles. (For some theoretical work, see the studies by Cole (1988) and Cole and Obstfeld (1991).) However, the friction in these papers is an exogenous limit on the type of assets that may be traded - only uncontingent bonds or none at all. Rather than exogenously limit the type of assets, our approach limits the amount of contingent claims of a particular type that can be sold - to the amount the debtor is willing to repay as captured by the enforcement constraints.

For comparison, though, we also describe and solve a model in which trade in contingent assets is restricted exogenously. We find that the effects of the endogenous enforcement constraints are quantitatively quite different from the effects of the exogenous asset market restrictions. For example, recall that in the data, both employment and investment comove positively across countries, and those data have generally been difficult to reproduce. Baxter (1995, p. 43) has written in her recent survey of international business cycles, that

It has proved particularly difficult to write down plausibly-parameterized models which can generate positive comovement of labor and investment across countries. . . . Thus a major challenge to the theory is to develop a model which can explain international comovement in labor input and investment.

In our study, both the complete markets model and the exogenous incomplete markets model fail to meet that challenge. But our model with endogenous incomplete markets generates 
strong positive comovements for both employment and investment.

\section{THE ECONOMIES}

We consider three variants of the standard two-country business cycle economy of Backus, Kehoe and Kydland (1992). To establish a benchmark, we first consider the standard complete markets setup. Then we incorporate endogenous market incompleteness arising from limited enforcement constraints. And finally, we incorporate exogenous market incompleteness, as do Baxter and Crucini (1995) and Kollmann (1996), by restricting trade in assets to simple uncontingent bonds. We do so to highlight the differences between our model with enforcement constraints and the literature's models.

\subsection{A complete markets economy}

Our theoretical world economy consists of two countries, $i=1,2$, each represented by a large number of identical, infinitely lived consumers and a production technology. The countries produce the same good, and their preferences and technologies have the same structure and parameter values. Although the technologies have the same form, they differ in two respects: in each country, the labor input consists only of domestic labor, and production is subject to country-specific technology shocks.

In each period $t$, the world economy experiences one of finitely many events $s_{t}$. We denote by $s^{t}=\left(s_{0}, \ldots, s_{t}\right)$ the history of events up through and including period $t$. The probability, as of period 0 , of any particular history $s^{t}$ is $\pi\left(s^{t}\right)$. The initial realization $s_{0}$ is given, so that $\pi\left(s_{0}\right)=1$. In each period $t$, the single good is produced in country $i$ using

inputs of capital $k_{i}\left(s^{t-1}\right)$ and domestic labor $l_{i}\left(s^{t}\right)$. Production is also subject to a country- 
specific random shock $A_{i}\left(s^{t}\right)$, which follows an exogenous process. Output in country $i$ at $s^{t}$ is given by

$$
F\left(k_{i}\left(s^{t-1}\right), A_{i}\left(s^{t}\right) l_{i}\left(s^{t}\right)\right)
$$

where $F$ is a standard constant returns to scale production function. Consumers in country $i$ have utility, or preferences, of the form

$$
\sum_{t=0}^{\infty} \sum_{s^{t}} \beta^{t} \pi\left(s^{t}\right) U\left(c_{i}\left(s^{t}\right), l_{i}\left(s^{t}\right)\right)
$$

where $c_{i}\left(s^{t}\right)$ denotes consumption by consumers in country $i$ at $s^{t}$ and $\beta$ denotes the discount factor. The resource constraints are given by

$$
\sum_{i=1,2}\left[c_{i}\left(s^{t}\right)+k_{i}\left(s^{t}\right)\right]=\sum_{i=1,2}\left[F\left(k_{i}\left(s^{t-1}\right), A_{i}\left(s^{t}\right) l_{i}\left(s^{t}\right)\right)+(1-\delta) k_{i}\left(s^{t-1}\right)\right]
$$

where $\delta$ is the per period depreciation rate of capital.

The complete markets version of this economy is defined in the standard way. The allocations solve the standard planning problem of maximizing a weighted sum of the discounted utilities

$$
\max \left[\lambda_{1} \sum_{t=0}^{\infty} \sum_{s^{t}} \beta^{t} \pi\left(s^{t}\right) U\left(c_{1}\left(s^{t}\right), l_{1}\left(s^{t}\right)\right)+\lambda_{2} \sum_{t=0}^{\infty} \sum_{s^{t}} \beta^{t} \pi\left(s^{t}\right) U\left(c_{2}\left(s^{t}\right), l_{2}\left(s^{t}\right)\right)\right]
$$

subject to the resource constraints (3). In our computations, we set the weights $\lambda_{1}=\lambda_{2}$. Given the symmetry of shocks, utility functions and production technologies we impose, the planning problem with these weights gives the same allocations that arise in a competitive equilibrium in which consumers in country $i$ own the initial capital in country $i$ and all the 
labor income in country $i$ and have no initial debts.

\subsection{An economy with enforcement constraints}

Consider next an economy with enforcement constraints. Here we lay out the economy and

show how to cast the problem of finding optimal allocations as a recursive programming problem.

This economy has, besides the resource constraints, enforcement constraints which require that at every point in time, each country prefers the allocation it receives relative to the allocation it could attain if it were in autarky, or self-sufficient, from then onward. These enforcement constraints are of the form

$$
\sum_{r=t}^{\infty} \sum_{s^{r}} \beta^{r-t} \pi\left(s^{r} \mid s^{t}\right) U\left(c_{i}\left(s^{r}\right), l_{i}\left(s^{r}\right)\right) \geq V_{i}\left(k_{i}\left(s^{t-1}\right), s^{t}\right)
$$

where $\pi\left(s^{r} \mid s^{t}\right)$ denotes the conditional probability of $s^{r}$ given $s^{t}, \pi\left(s^{t} \mid s^{t}\right)=1$, and $V_{i}\left(k_{i}\left(s^{t-1}\right), s^{t}\right)$ denotes the value of autarky from $s^{t}$ onward, which is given by the value of utility in the problem of choosing $k_{i}\left(s^{r}\right), l_{i}\left(s^{r}\right)$ and $c_{i}\left(s^{r}\right)$ for all $s^{r}$ with $r \geq t$ to solve

$$
V_{i}\left(k_{i}\left(s^{t-1}\right), s^{t}\right)=\max \sum_{r=t}^{\infty} \sum_{s^{r}} \beta^{t} \pi\left(s^{r} \mid s^{t}\right) U\left(c_{i}\left(s^{r}\right), l_{i}\left(s^{r}\right)\right)
$$

subject to

$$
c_{i}\left(s^{r}\right)+k_{i}\left(s^{r}\right) \leq F\left(k_{i}\left(s^{r-1}\right), A_{i}\left(s^{r}\right) l_{i}\left(s^{r}\right)\right)+(1-\delta) k_{i}\left(s^{r-1}\right)
$$

with $k_{i}\left(s^{t-1}\right)$ given.

Consider the problem of maximizing a weighted sum of utilities subject to the resource 
constraints and the enforcement constraints; namely, choose allocations $\left\{c_{i}\left(s^{t}\right), l_{i}\left(s^{t}\right), k_{i}\left(s^{t}\right)\right\}$ for $i=1,2$ and all $s^{t}$ to solve this planning problem:

$$
\max \left[\lambda_{1} \sum_{t=0}^{\infty} \sum_{s^{t}} \beta^{t} \pi\left(s^{t}\right) U\left(c_{1}\left(s^{t}\right), l_{1}\left(s^{t}\right)\right)+\lambda_{2} \sum_{t=0}^{\infty} \sum_{s^{t}} \beta^{t} \pi\left(s^{t}\right) U\left(c_{2}\left(s^{t}\right), l_{2}\left(s^{t}\right)\right)\right]
$$

subject to (3) for all $s^{t}$, and (5) for $i=1,2$ and all $s^{t}$, where $\lambda_{1}$ and $\lambda_{2}$ are nonnegative initial weights.

One way to approach this problem is to make the shocks Markovian and then recast the problem as a standard dynamic programming problem with a state that consists of the current capital stocks and the current shocks. Unfortunately, in that formulation, future decision variables, like consumption and leisure, enter the current enforcement constraint. This feature makes the standard dynamic programming approach inapplicable. In an early contribution, Kydland and Prescott (1980) study an optimal tax problem with this feature and show that if the state space is expanded to include an extra (pseudo) state variable, then the problem has a solution that is stationary in the expanded state space. Marcet and Marimon (1999) extend this approach to a variety of contexts. In our context, the additional state variable turns out to be the ratio of the sums of the multipliers on the enforcement constraints. When we make the shocks Markovian and add this new state variable to the standard ones, namely, the capital stocks and the shocks, we have a recursive problem.

We develop our approach as follows. Letting $\beta^{t} \pi\left(s^{t}\right) \mu_{i}\left(s^{t}\right)$ denote the multipliers on the enforcement constraints, we can write the Lagrangian as (6) plus the sum of terms relating 
to the enforcement constraints of the form

$$
\beta^{t} \pi\left(s^{t}\right) \mu_{i}\left(s^{t}\right)\left[\sum_{r=t}^{\infty} \sum_{s^{r}} \beta^{r-t} \pi\left(s^{r} \mid s^{t}\right) U\left(c_{i}\left(s^{r}\right), l_{i}\left(s^{r}\right)\right)-V_{i}\left(k_{i}\left(s^{t-1}\right), s^{t}\right)\right]
$$

for all $t$ and $s^{t}$, plus standard terms relating to the resource constraints. Since $\pi\left(s^{r}\right)=$ $\pi\left(s^{r} \mid s^{t}\right) \pi\left(s^{t}\right)$, we can regroup terms and write the Lagrangian as

$$
\sum_{t=0}^{\infty} \sum_{s^{t}} \sum_{i} \beta^{t} \pi\left(s^{t}\right)\left[M_{i}\left(s^{t-1}\right) U\left(c_{i}\left(s^{t}\right), l_{i}\left(s^{t}\right)\right)+\mu_{i}\left(s^{t}\right)\left[U\left(c_{i}\left(s^{t}\right), l_{i}\left(s^{t}\right)\right)-V_{i}\left(k_{i}\left(s^{t-1}\right), s^{t}\right)\right]\right]
$$

plus standard terms relating to the resource constraints. Here $M_{i}\left(s^{t}\right)$ is defined recursively by

$$
M_{i}\left(s^{t}\right)=M_{i}\left(s^{t-1}\right)+\mu_{i}\left(s^{t}\right)
$$

for $t \geq 0$, and $M_{i}\left(s^{-1}\right)$ equals $\lambda_{i}$. Notice that the $M_{i}\left(s^{t}\right)$ are simply the original planning weights $\lambda_{i}$ plus the sum of the past multipliers on the enforcement constraints along the history $s^{t}$. The first-order conditions are summarized by

$$
\begin{gathered}
\frac{U_{1 c}\left(s^{t}\right)}{U_{2 c}\left(s^{t}\right)}=\frac{M_{2}\left(s^{t-1}\right)+\mu_{2}\left(s^{t}\right)}{M_{1}\left(s^{t-1}\right)+\mu_{1}\left(s^{t}\right)} \\
\frac{U_{i l}\left(s^{t}\right)}{U_{i c}\left(s^{t}\right)}=F_{i l}\left(s^{t}\right) \\
U_{i c}\left(s^{t}\right)=\beta \sum \pi\left(s^{t+1} \mid s^{t}\right)\left[\frac{M_{i}\left(s^{t+1}\right)}{M_{i}\left(s^{t}\right)} U_{i c}\left(s^{t+1}\right)\left[F_{i k}\left(s^{t+1}\right)+1-\delta\right]-\frac{\mu_{i}\left(s^{t+1}\right)}{M_{i}\left(s^{t}\right)} V_{i k}\left(s^{t+1}\right)\right]
\end{gathered}
$$

for $i=1,2$ for all $s^{t}$, together with the complementary slackness conditions. In these firstorder conditions, we have used the abbreviation $U_{i c}\left(s^{t}\right)$ for $\partial U\left(c_{i}\left(s^{t}\right), l_{i}\left(s^{t}\right)\right) / \partial c_{i}$, and we have 
used similar abbreviations for other terms. For convenience, we normalize these multipliers by defining $v_{i}\left(s^{t}\right)=\mu_{i}\left(s^{t}\right) / M_{i}\left(s^{t}\right)$ and $z\left(s^{t}\right)=M_{2}\left(s^{t}\right) / M_{1}\left(s^{t}\right)$. This allows us to keep track of only the relative weight $z\left(s^{t}\right)$ in the state instead of the two absolute weights $M_{i}\left(s^{t}\right)$. The transition law for $M_{i}\left(s^{t}\right)$ can be written as $\left[1-v_{i}\left(s^{t}\right)\right] M_{i}\left(s^{t}\right)=M_{i}\left(s^{t-1}\right)$, so the transition law for $z\left(s^{t}\right)$ can be written as

$$
z\left(s^{t}\right)=\frac{1-v_{1}\left(s^{t}\right)}{1-v_{2}\left(s^{t}\right)} z\left(s^{t-1}\right) .
$$

We will refer to $z\left(s^{t}\right)$ as the relative weight on country 2 consumers. With these normalized multipliers, we can summarize the first-order conditions by (9),

$$
\frac{U_{1 c}\left(s^{t}\right)}{U_{2 c}\left(s^{t}\right)}=\frac{1-v_{1}\left(s^{t}\right)}{1-v_{2}\left(s^{t}\right)} z\left(s^{t-1}\right)
$$

in place of (8) and

$$
U_{i c}\left(s^{t}\right)=\beta \sum \pi\left(s^{t+1} \mid s^{t}\right)\left[\frac{U_{i c}\left(s^{t+1}\right)}{1-v_{i}\left(s^{t+1}\right)}\left[F_{i k}\left(s^{t+1}\right)+1-\delta\right]-\frac{v_{i}\left(s^{t+1}\right)}{1-v_{i}\left(s^{t+1}\right)} V_{i k}\left(s^{t+1}\right)\right]
$$

in place of (10) together with the transition law (11) and the complementary slackness conditions with the normalized multipliers.

We will focus on economies in which the underlying shocks are Markov, so that the conditional probability $\pi\left(s^{t} \mid s^{t-1}\right)$ can be written as $\pi\left(s_{t} \mid s_{t-1}\right)$. In such economies, the solution to the programming problem in (6) can be characterized recursively by policy rules for the allocations of the form $c_{i}\left(x_{t}\right), l_{i}\left(x_{t}\right), k_{i}\left(x_{t}\right)$ together with policy rules for the relative weight $z\left(x_{t}\right)$ and the multipliers $v_{i}\left(x_{t}\right)$, where the state is $x_{t}=\left(z\left(s^{t-1}\right), k_{1}\left(s^{t-1}\right), k_{2}\left(s^{t-1}\right), s_{t}\right)$. These 
policy functions satisfy the first-order conditions (9), (12) and (13) and the transition law (11) together with the resource constraints (3), the enforcement constraints (5) and the complementary slackness conditions on the multipliers.

In a separate appendix, we give one interpretation of how this economy can be decentralized. In the decentralization, the government of each country can tax payments made to foreigners and capital income and then rebate the proceeds to its citizens as a lump sum. Except for these government policies, private markets function perfectly in this economy. This set of policies turns out to be sufficient for the decentralization of the optimal plan as the outcome of a dynamic game. In this economy, the governments in the two countries sequentially choose policy in an optimal fashion to maximize the welfare of their residents. We set up and define a sustainable equilibrium for this economy along the lines of that considered by Chari and Kehoe (1990, 1993), who have extended the work of Abreu (1988) to economies with competitive private agents. We show that the allocations that satisfy the programming problem (6) are sustainable allocations. The right side of the enforcement constraints corresponds to the value of the worst sustainable equilibrium.

\subsection{A bond economy}

Consider next an economy in which the menu of assets that are traded internationally is exogenously restricted to a single uncontingent bond. The remaining primitives are the same as in the economy just described.

In this economy, the representative agents in the two countries maximize their expected 
lifetime utilities, given in (2), subject to the following constraints:

$$
c_{i}\left(s^{t}\right)+k_{i}\left(s^{t}\right)+q\left(s^{t}\right) b_{i}\left(s^{t}\right) \leq w\left(s^{t}\right) l_{i}\left(s^{t}\right)+\left[r_{i}\left(s^{t}\right)+1-\delta\right] k_{i}\left(s^{t-1}\right)+b_{i}\left(s^{t-1}\right)
$$

where $w_{i}\left(s^{t}\right)$ and $r_{i}\left(s^{t}\right)$ are the wage and the rental rate on capital in country $i, q\left(s^{t}\right)$ is the period $t$ price of the uncontingent bond that pays one unit of the consumption good in period $t+1$ regardless of the state of the world and $b_{i}\left(s^{t}\right)$ denotes the quantity of uncontingent bonds

purchased at $t$ by a consumer in country $i$. We also bound the borrowing of agents by the condition $b\left(s^{t}\right) \geq-\bar{b}$, where $\bar{b}$ is some large positive number.

In the two countries, firms solve the standard static profit-maximization problem, and bond market-clearing requires that $b_{1}\left(s^{t}\right)+b_{2}\left(s^{t}\right)=0$. An equilibrium for this economy is defined in the standard way.

\section{PARAMETER VALUES AND COMPUTATION}

Now we briefly describe the procedures we use to select benchmark parameter values, listed in Table 1, and to compute a solution to the programming problem.

The specification of preferences and technology is standard and follows Backus, Kehoe and Kydland (1992). The utility function is $U(c, l)=\left[c^{\gamma}(1-l)^{1-\gamma}\right]^{1-\sigma} /(1-\sigma)$, and the production function is $F(k, A l)=k^{\alpha}(A l)^{1-\alpha}$. (See Table 1 for details.)

In terms of the productivity shocks, Backus, Kehoe and Kydland (1992), Baxter and Crucini (1995) and Kollmann (1996) assume that the technology shocks in the two countries 
$\left(A_{1 t}, A_{2 t}\right)$ follow a vector autoregressive (VAR) process of the form

$$
\left[\begin{array}{c}
\log A_{1 t+1} \\
\log A_{2 t+1}
\end{array}\right]=\left[\begin{array}{ll}
a_{1} & a_{2} \\
a_{2} & a_{1}
\end{array}\right]\left[\begin{array}{c}
\log A_{1 t} \\
\log A_{2 t}
\end{array}\right]+\left[\begin{array}{c}
\varepsilon_{1 t+1} \\
\varepsilon_{2 t+1}
\end{array}\right] .
$$

The innovations $\varepsilon_{t}=\left(\varepsilon_{1 t}, \varepsilon_{2 t}\right)$ are serially independent, multivariate normal random variables with contemporaneous covariance matrix $V$, which allows for contemporaneous correlation between innovations in the home country and the foreign country. Thus, the shocks are stochastically related through the off-diagonal element $a_{2}$, called the spillover parameter, and the off-diagonal elements of the covariance matrix $V$.

Baxter and Crucini (1995) and Kollmann (1996) use the production function and estimates of the inputs to form time series on $A_{i t}$ for the United States and for some European countries. These researchers find little evidence of spillover, in that $a_{2}$ is close to zero, and some evidence for substantial persistence, with $a_{1}$ large. Kollmann (1996) focuses on $a_{1}=.95$ while Baxter and Crucini report results for a range of parameters for $a_{1}$ around .95 . We follow these studies and as a baseline set $a_{1}=.95$ and $a_{2}=0$. In our sensitivity analyses, we explore several variations around this baseline, both with higher persistence, by setting $a_{1}=.99$ and $a_{2}=0$ (termed high persistence), and with nonzero spillover, by setting $a_{1}=.85$ and $a_{2}=.15$ (termed high spillover), as well as with the original estimates of Backus, Kehoe and Kydland (1992) (termed $B K K$ ), with $a_{1}=.906$ and $a_{2}=.088$. In terms of the covariance matrix, we set $\operatorname{var} \varepsilon_{1}=\operatorname{var} \varepsilon_{2}=.007^{2}$ and $\operatorname{corr}\left(\varepsilon_{1}, \varepsilon_{2}\right)=.25$, which are in line with the estimates of these three studies.

Our computational procedure makes it convenient to use a discrete state Markov 
chain to represent the stochastic technology shocks. We let total factor productivity in both countries take on three values. We choose the values of the states and the transition probabilities by simulating the VAR 50 million times and then estimating the Markov chain on the simulated data by maximum likelihood.

The computational procedure we use to find the optimal allocations in the economy with enforcement constraints is a version of the policy function iteration algorithm, modified to handle enforcement constraints. (For comparison purposes, we compute the equilibria for all three economies using the same method.)

Let $x=\left(z, k_{1}, k_{2}, s\right)$ be the state of the economy. Our procedure finds policy functions for current consumption and labor $c_{i}(x), l_{i}(x)$, for future capital and relative weight $k_{i}^{\prime}(x), z^{\prime}(x)$ and for multipliers $v_{i}(x)$. For convenience, we also define value functions $W_{i}(x)$ that satisfy

$$
W_{i}(x)=U\left(c_{i}(x), l_{i}(x)\right)+\beta \sum_{s^{\prime}} \pi\left(s^{\prime} \mid s\right) W_{i}\left(x^{\prime}\right)
$$

All of these functions need to satisfy the first-order conditions (9), (12) and (13) and the transition law (11) together with the resource constraints (3), the enforcement constraints (5) and the complementary slackness conditions on the multipliers. In practice, we define a grid $X$ on the state space and restrict our search within the class of functions that take arbitrary values for every $x \in X$ and are equal to the piecewise bilinear interpolation of those values for every $x \notin X$. These functions are completely characterized over the entire state space by specifying their value for every $x \in X$.

We start with a guess for the solution to the planning problem (6) without enforcement constraints. We denote the initial guess by a set of values $\left(c_{i}^{0}(x), l_{i}^{0}(x), k_{i}^{\prime 0}(x), W_{i}^{0}(x), v_{i}^{0}(x)\right)$ 
for every $x \in X$. Given the first-order conditions and the initial guess, we find a new set of policy functions, value functions and multiplier functions $\left(c_{i}^{1}(x), l_{i}^{1}(x), k_{i}^{\prime 1}(x), W_{i}^{1}(x), v_{i}^{1}(x)\right)$ as follows. Since we do not know in advance the binding pattern of the enforcement constraints, we consider separately the three possible binding patterns: neither constraint binds, that of the home country binds but that of the foreign country is slack and that of the foreign country binds but that of the home country is slack. (Clearly, both cannot bind simultaneously.) First, for each $x \in X$, we compute allocations assuming that neither enforcement constraint binds in this period and check if the constructed allocations satisfy the enforcement constraints

$$
U\left(c_{i}, l_{i}\right)+\beta \sum_{s^{\prime}} \pi\left(s^{\prime} \mid s\right) W_{i}^{0}\left(x^{\prime}\right) \geq V_{i}\left(k_{i}, s\right)
$$

for $i=1,2$. If these allocations satisfy both constraints, then we define them to be the new set of allocations for this $x$, we set the new multipliers $v_{i}^{1}(x)=0$ and we define the value function $W_{i}^{1}(x)$ by the left side of (15). If, say, the constructed allocations satisfy the enforcement constraint for country 1 but not that for country 2 , then we set the multiplier on country 1's constraint to zero, $v_{1}^{1}(x)=0$, and we write the enforcement constraint of country 2 as an equality, namely,

$$
U\left(c_{2}, l_{2}\right)+\beta \sum_{s^{\prime}} \pi\left(s^{\prime} \mid s\right) W_{2}^{1}\left(x^{\prime}\right)=V_{i}\left(k_{2}, s\right) .
$$

We define the new value functions by the left side of (15) for country 1 and the left side of (16) for country 2.

If the allocations constructed under the assumption that neither enforcement constraint binds satisfy the enforcement constraint for country 2 but not that for country 1 , 
then we set the multiplier on country 2's constraint to zero, $v_{2}^{1}(x)=0$, and proceed analogously. We repeat this procedure for every $x \in X$ and then compare the vectors $\left(c_{i}^{1}(x)\right.$, $\left.l_{i}^{1}(x), k_{i}^{1}(x), W_{i}^{1}(x), v_{i}^{1}(x)\right)$ with $\left(c_{i}^{0}(x), l_{i}^{0}(x), k_{i}^{0}(x), W_{i}^{0}(x), v_{i}^{0}(x)\right)$. If, on each grid point, these vectors are equal up to a small positive number, we stop; otherwise, we set the initial guess equal to the new set of policy, multiplier and value functions. We keep iterating until the value functions and policy functions converge. (See Kehoe and Perri (2000) for details.)

\section{FINDINGS}

Now we compare the quantitative properties of our theoretical world economies with those of the data. In general, we find that endogenous enforcement constraints go a long way toward resolving the anomalies while the exogenous asset market restrictions do not.

In Tables $2-3$, the statistics reported in the first nine rows in the data column are from U.S. quarterly time series. The international correlations in the tables' remaining rows of that column refer to the correlations between U.S. variables and the same variables for an aggregate of 15 European countries. For all the statistics, the time period is from the first quarter of 1970 to the last quarter of 1998. For more details on the data sources, see the following appendix. The numbers in parentheses below the U.S. statistics are the NeweyWest standard errors that were generated by posing the estimation of the data moments as a generalized-method-of moments problem.

\subsection{Three basic economies}

We start with a comparison of the complete markets economy and the data. In Table 2, we see three major discrepancies for this economy. Two of them are the two discrepancies labeled anomalies by Backus, Kehoe and Kydland (1993): Consumption's correlation across 
countries is substantially higher than output's in the model (.28 vs. -.46), while in the data the reverse is true (.32 vs. .51). And the cross-country correlations of investment and employment are negative in the model $(-.99$ and -.58 , respectively), while in the data these correlations are positive (.29 and .43 , respectively). The third discrepancy is another wellknown difference between standard business cycle models and the data: Both net exports and investment are much more volatile in the model than in the data, with net exports being more than 85 times as volatile as the data (13.04 vs. .15) and investment being about 8 times as volatile (25.23 vs. 3.24$)$.

Consider next the economy in which asset trade is restricted to uncontingent bonds (referred to as the bond economy in the tables). In this economy, the three discrepancies remain substantially unchanged. Output is still less correlated across countries than is consumption, but the discrepancy with the data is somewhat smaller than that in the complete markets economy. The negative cross correlation of investment is the same as that with complete markets, and the cross correlation of employment is only slightly higher. And net exports and investment are still much more volatile in the model than in the data.

Consider now the economy with enforcement constraints (referred to as the enforcement economy in the tables). In terms of the cross-country correlations, note that adding enforcement constraints has made consumption's much closer to output's, although consumption's is still slightly bigger (.29 vs. .25). Also, relative to the complete markets and bond economies, the enforcement constraint has changed the cross correlations of investment and employment from negative to positive. And finally, introducing enforcement constraints drastically reduces the volatility of net exports and investment relative to their volatility in the complete markets economy. Now the volatility of net exports is actually smaller in the model 
than in the data (.06 vs. .15) and the volatility of investment is about right (3.04 vs. 3.24).

In these dimensions, the enforcement economy has gone a long way toward reducing the discrepancies between the theory and the data. The main remaining discrepancy between the enforcement economy and the data is that the variable net exports is procyclical in the model but countercyclical in the data. (Its correlation with GDP is .27 in the model, but -.36 in the data.)

\subsection{Adding adjustment costs}

Again, it is well known that the volatilities of investment and net exports are much higher in standard one-good international business cycle models than in the data. In these models, capital flows rapidly to the country with the higher productivity shock. Usually in such models, these volatilities are reduced by adding to the model costs to change capital, or adjustment costs. But incorporating enforcement problems in a model naturally introduces forces inhibiting the flow of capital to more productive countries. In this sense, once a model has enforcement problems, it does not need tacked on adjustment costs to smooth out investment and net exports.

Nevertheless, the current literature has adjustment costs. So we wonder, how does the enforcement economy (with its natural forces inhibiting capital flows) compare to the complete markets economy and the bond economy with adjustment costs added on? With that in mind, we modify the resource constraints of the complete markets and bond economies to be

$$
\sum_{i=1,2}\left[c_{i}\left(s^{t}\right)+x_{i}\left(s^{t}\right)\right]=\sum_{i=1,2}\left[F\left(k_{i}\left(s^{t-1}\right), A_{i}\left(s^{t}\right) l_{i}\left(s^{t}\right)\right)\right]
$$


where investment in country $i, x_{i}\left(s^{t}\right)$, adds to new capital according to the accumulation rule:

$$
k_{i}\left(s^{t}\right)=(1-\delta) k_{i}\left(s^{t-1}\right)+x_{i}\left(s^{t}\right)-\phi k_{i}\left(s^{t-1}\right)\left[\frac{x_{i}\left(s^{t}\right)}{k_{i}\left(s^{t-1}\right)}-\delta\right]^{2} .
$$

Here, $\phi$ is the parameter that determines the magnitude of capital adjustment costs.

In the last two columns of Table 2, we report the statistics for the complete markets economy and the bond economy with adjustment costs, with $\phi$ chosen for each model so that the volatility of investment relative to the volatility of GDP is similar to that in the data. Clearly, in both models, the adjustment costs inhibit flows of investment goods so that the volatility of net exports is also more in line with the data (.36 and .33 vs. .15$)$. In terms of the cross-country correlations, the anomalies still remain, although they are somewhat diminished. In both the complete markets and bond economies with adjustment costs, the cross-country correlation of consumption is still higher than that of output, and this anomaly is more pronounced in the complete markets economy (.77 vs. .09) and in the bond economy (.62 vs. .12) than in the economy with enforcement constraints (.29 vs. .25). In both the complete markets and the bond economies, the adjustment costs increase the cross correlation for investment compared to the corresponding economies without adjustment costs, but in both economies, that correlation remains negative $(-.17$ and -.09$)$. The adjustment costs have a similar effect on the cross correlation of employment.

\subsection{Responses to a productivity shock}

We can get some intuition for why the economies have these properties by examining the impulse responses of variables in the economies to a positive productivity shock to country 1. We refer to country 1 as the home country and country 2 as the foreign country. We focus 
on just the last three of the five economies we have examined: the enforcement economy, the complete markets economy with adjustment costs and the bond economy with adjustment costs. We suppose that in all three economies, both countries have had their productivity equal to the average (mean) level for a long time, and then in period 0, the home country switches to high productivity while the foreign country does not. Starting with this configuration of shocks along with the associated capital stocks and the relative weight $z=1$ in period 0 , we use simulations to calculate the conditional expectation of each variable in period $t$ for $t=0,1, \ldots$

In Figures 1-7, we plot for the three economies the percentage changes in the variables due to the productivity increase in the home country. In Figure 1 we see that on impact, the productivity in that country increases by about $1.5 \%$ and then slowly decreases to its mean. The productivity in the foreign country, meanwhile, does not change because there are no spillovers $\left(a_{2}=0\right)$.

In Figures $2 a$ and $b$ we plot the responses for output in both countries for the three economies. In the home country in all three, we see that the positive productivity shock of about $1.5 \%$ leads to a substantial increase in output, of about $2.4 \%$ on impact. In the foreign country, in contrast, output initially drops a bit in the complete markets and bond economies, then becomes slightly positive after several years, while in the enforcement economy output is positive after a quarter.

In Figures $3 a$ and $b$ we see that in the complete markets economy, risk-sharing leads foreign consumption to rise along with home consumption after a positive productivity shock in the home country. In the bond economy, risk-sharing is somewhat inhibited, so that foreign consumption rises by less in that economy than under complete markets. In the enforcement 
economy, risk-sharing is greatly inhibited; consumption in the foreign country is essentially constant. This inhibition of risk-sharing is what lies behind the cross-country correlations for consumption discussed above.

In Figures 4 and 5 we see that in all three economies, the home country productivity shock leads to a rise in home country inputs (investment and employment), with the smallest initial rise in the enforcement economy. In the foreign country, at the same time, inputs have different patterns across the economies. In Figures $4 b$ and $5 b$ we see that in the foreign country in the complete markets and bond economies, both investment and employment drop initially, while in the enforcement economy, investment rises only slightly and employment remains essentially unchanged.

In Figure 6 we see that in the complete markets and bond economies, the shock leads to a home country trade deficit (negative net exports), while in the enforcement economy it leads to a home country trade surplus.

Finally, in Figure 7 we plot the impulse response for the ratio of the marginal utility of consumption in the foreign country to that in the home country. This ratio summarizes the extent of risk-sharing in the three economies. In the complete markets economy, risksharing is perfect, and the productivity shock does not change the ratio of marginal utilities between the two countries. Both the bond and enforcement economies, however, experience persistent deviations from perfect risk-sharing, so that the ratio of marginal utilities is no longer equalized. The deviations are much more severe in the enforcement economy than in the bond economy in the sense that the ratio of marginal utility is everywhere higher in the enforcement economy.

To understand the economics behind these responses, consider first the complete mar- 
kets model. The positive productivity shock in the home country naturally increases the productivity of capital and labor, so shifting resources to this country is optimal. Thus, the capital stock in that country increases, both by domestic residents saving more and by more investment flowing in from abroad. The net inflow of investment leads to a trade deficit in the home country. In the foreign country, meanwhile, investment initially falls. With regard to labor, the temporarily high productivity of labor in the home country makes it optimal to increase labor effort at home and decrease it abroad. Because of risk-sharing, the increased output in the home country also leads to increased consumption in the foreign country. Since consumption and labor are complements in utility, consumption increases substantially more at home than abroad. Overall, the shifting of resources from the foreign country to the home country helps explain the small or negative correlations between inputs and between outputs.

In the bond economy, the responses generally move in the same direction as those in the complete markets economy. However, the restrictions on asset trade make risk-sharing more difficult in the bond economy, so all of the responses are somewhat dampened.

In the enforcement economy, the need to satisfy the enforcement constraints leads to much more severe restrictions on risk-sharing and investment flows. Consider the restrictions on the shifting of resources. Suppose, for intuition's sake, that a planner ignores the enforcement constraints and tries to implement the complete markets allocations. For the country with the positive shock, the home country, the high and persistent increase in productivity increases the value of autarky, making default an attractive option. Moreover, if the planner starts shifting capital to this country, the value of autarky rises even higher, making default an even better option. Since this allocation violates the enforcement constraints, the planner restricts the investment flows to the home country in order to keep down the value of autarky. 
(This is the interpretation of the last term on the right side of (13).) Moreover, the planner actually builds up the capital stock in the foreign country in order to increase the value to the home country of sticking to the implicit risk-sharing agreement. These patterns of investment lead the home country to run a trade surplus instead of a deficit.

Consider next the effects of the enforcement constraints on consumption. Under complete markets, risk-sharing dictates that consumers in the home country, with the positive shock, should share much of their gains with those in the foreign country, without the shock. If the planner is to meet the enforcement constraints, this large risk-sharing is not feasible. To meet the enforcement constraints, then, the planner must increase the discounted value of utility of the home country by increasing its relative weight. This leads to higher present consumption as well as higher future consumption in that country (through a persistent movement in $z$ ). The movement in the relative weight implies that the planner increases the ratio of foreign marginal utility to home marginal utility in a way that persists over time. As the productivity shock starts to decay, the value of autarky decreases, and the planner then lowers the relative weight of the home country.

\subsection{Sensitivity analyses}

In Table 3 we report the results of a sensitivity analysis with respect to the structure of technology shocks in the enforcement economy and the bond economy with adjustment costs. We experiment with the alternative shock processes described above.

In the high persistence experiment (in which we increase $a_{1}$ from .95 to .99 ), there is little change from the baseline in either the enforcement or the bond economy. In the bond economy, the increased persistence lowers the gap a bit between the consumption and output 
cross-country correlations, but it does so at the expense of making inputs more negatively correlated.

In both economies, increasing the spillover in the high spillover experiment (by increasing $a_{2}$ from 0 to .15) increases the gap between the consumption and output crosscountry correlations. Partly this is because, even without trade between countries, a shock to the home country signals foreign consumers that their output will increase in the future. This leads foreign consumers to increase their consumption in anticipation of this spillover.

The $B K K$ experiment (in which $a_{1}$ is decreased to .906 and $a_{2}$ is increased to .088 ) has a similar effect on the consumption and output correlations as does the high spillover experiment. In addition, the BKK experiment leads to lower cross-country correlations of inputs in both economies.

We also conducted sensitivity analyses for other parameters in the model, including the discount factor $\beta$, the curvature parameter $\sigma$, and the capital share parameter $\alpha$ which are available upon request. Overall, little changes.

\section{CONCLUSIONS}

We have investigated a new direction for the quantitative equilibrium approach to international business cycles. We have found that limited enforcement of contracts in international credit markets goes a long way toward resolving some of the anomalies in the literature.

We have found that the allocations that can be enforced by threat of exclusion from future intertemporal and interstate trade are quite different from those under complete markets. Our approach and our results are different from those of other researchers who have investigated the importance of incomplete markets in international business cycle models (Baxter 
and Crucini (1995)). Other researchers have found that if the assets that are tradeable internationally are restricted exogenously to a single uncontingent bond, then the equilibrium allocations are, for the most part, similar to those arising under complete markets. In contrast, we have found that introducing enforcement constraints drives the economy far away from the complete markets allocation regardless of the parameters of the model.

Quantitatively, we have found that a model with enforcement constraints makes two major contributions. It reproduces the data's positive cross-country comovements of factors of production. And it comes closer than existing models to reproducing the data's patterns of cross-country comovements of consumption and output.

The main failing of the model with enforcement constraints is that its constraints reduce the international flow of investment so much that they actually produce the wrong sign in the relation between net exports and output: the model predicts a positive comovement between net exports and output while the data have the opposite. One potential explanation for this failing is that the model's penalties for exclusion from asset trade are not severe enough. One can imagine other ways that countries interact besides this type of trade, such as spot trade of goods, international defence treaties and so on. For countries that have more intertwined relationships, the potential losses by being excluded from these relationships are more severe, and perhaps greater international flows of investment would exist. The difficult problem is to design a model with imperfections that tend to inhibit the sharing of consumption risk relatively more while at the same time inhibiting the flows of investment relatively less than in the current setup. 


\section{APPENDIX}

We collected data series for output, consumption, investment and employment for the United States and an aggregate of 15 European countries (Austria, Belgium, Denmark, Finland, France, Germany, Greece, Ireland, Italy, Luxembourg, the Netherlands, Portugal, Spain, Sweden, and the United Kingdom). The data we used cover the period from the first quarter of 1970 through the fourth quarter of 1998.

The U.S. series are from the Federal Reserve Bank of St. Louis economic database (known as FRED), and the particular series used are gross domestic product, personal consumption expenditures, fixed private investment (all real) and civilian employment.

The series for the aggregate of 15 European countries are from the Organisation for Economic Co-operation and Development publication, Main Economic Indicators (Aggregate EU15), and they are gross domestic product, private final consumption expenditure, gross fixed capital formation (all real) and civilian employment.

We also collected exports and imports (nominal) of the United States toward the 15 European countries by aggregating the U.S. imports and the imports by country reported in the International Monetary Fund publication, Directions of Trade Statistics. The statistics relative to net exports refer to U.S. exports toward EU15 minus U.S. imports from EU15 all divided by U.S. GDP (nominal). 
Acknowledgments. The views expressed herein are those of the authors and not necessarily those of the Federal Reserve Bank of Minneapolis or the Federal Reserve System. 


\section{REFERENCES}

ABREU, D. (1988), "On the Theory of Infinitely Repeated Games With Discounting", Econometrica, 56, 383-396.

ALVAREZ, F. and JERMANN, U. J. (1998), "Quantitative Asset Pricing Implications of Endogenous Solvency Constraints" (Research Working Paper: 99/05, Federal Reserve Bank of Philadelphia).

ALVAREZ, F. and JERMANN, U. J. (2000), "Efficiency, Equilibrium, and Asset Pricing with Risk of Default", Econometrica, 68, 775-797.

ATTANASIO, O. and RÍOS-RULL, J.-V. (2000), "Consumption Smoothing in Island Economies: Can Public Insurance Reduce Welfare?", European Economic Review, 44, 12251258.

BACKUS, D. K., KEHOE, P. J. and KYDLAND, F. E. (1992), "International Real Business Cycles", Journal of Political Economy, 100, 745-775.

BACKUS, D. K., KEHOE, P. J. and KYDLAND, F. E. (1993), "International Business Cycles: Theory vs. Evidence", Federal Reserve Bank of Minneapolis Quarterly Review, 17 (Fall), 14-29.

BAXTER, M. (1995), "International Trade and Business Cycles" (Working Paper 5025, National Bureau of Economic Research). Also (1995) in G. M. Grossman and K. Rogoff (eds.), Handbook of International Economics, Vol. 3 (Amsterdam: North-Holland), 1801-1864.

BAXTER, M. and CRUCINI, M. J. (1995), "Business Cycles and the Asset Structure of Foreign Trade", International Economic Review, 36, 821-854. 
CHARI, V. V. and KEHOE, P. J. (1990), "Sustainable Plans", Journal of Political Economy, 98, $783-802$.

CHARI, V. V. and KEHOE, P. J. (1993), "Sustainable Plans and Mutual Default", Review of Economic Studies, 60, 175-195.

COLE, H. L. (1988), "Financial Structure and International Trade", International Economic Review, 29, 237-259.

COLE, H. L. and OBSTFELD, M. (1991), "Commodity Trade and International Risk Sharing: How Much Do Financial Markets Matter?", Journal of Monetary Economics, 28, $3-24$.

EATON, J. and FERNANDEZ, R. (1995), "Sovereign Debt", in G. M. Grossman and K. Rogoff (eds.), Handbook of International Economics, Vol. 3 (Amsterdam: NorthHolland), 2031-2077.

EATON, J. and GERSOVITZ, M. (1981), "Debt With Potential Repudiation: Theoretical and Empirical Analysis", Review of Economic Studies, 48, 289-309.

HEATHCOTE, J. and PERRI, F. (2000), "Financial Autarky and International Business Cycles" (Working Paper 320, Stockholm School of Economics).

KEHOE, P. J. and PERRI, F. (2000), "International Business Cycles with Endogenous Incomplete Markets" (Working Paper 7870, National Bureau of Economic Research).

KEHOE, T. J. and LEVINE, D. K. (1993), "Debt-Constrained Asset Markets", Review of Economic Studies, 60, 865-888.

KEHOE, T. J. and LEVINE, D. K. (Forthcoming), "Liquidity Constrained versus Debt Constrained Markets", Econometrica.

KOCHERLAKOTA, N. R. (1996), "Implications of Efficient Risk Sharing Without Commit- 
ment", Review of Economic Studies, 63, 595-609.

KOLLMANN, R. (1996), "Incomplete Asset Markets and the Cross-Country Consumption Correlation Puzzle", Journal of Economic Dynamics and Control, 20, 945-961.

KYDLAND, F. E. and PRESCOTT, E. C. (1980), "Dynamic Optimal Taxation, Rational Expectations and Optimal Control", Journal of Economic Dynamics and Control, 2, 79-91.

LIGON, E., THOMAS, J. P. and WORRALL, T. (1997), "Informal Insurance Arrangements in Village Economies" (Working Paper 97/08, Department of Economics, Keele University).

LIGON, E., THOMAS, J. P. and WORRALL, T. (2000), "Mutual Insurance, Individual Savings, and Limited Commitment", Review of Economic Dynamics, 3, 216-246.

MANUELLI, R. E. (1986), "Topics in Intertemporal Economics" (Unpublished Ph.D. dissertation, University of Minnesota).

MARCET, A. and MARIMON, R. (1999), "Recursive Contracts" (Manuscript, Universitat Pompeu Fabra).

STOCKMAN, A. C. and TESAR, L. (1995), "Tastes and Technology in a Two-Country Model of the Business Cycle: Explaining International Comovements", American Economic Review, 85, 168-185. 
TABLE 1. Parameter values

\begin{tabular}{lll}
\hline Experiments & \multicolumn{1}{c}{ Parameters } \\
\hline Baseline Experiments & Preferences & $\beta=.99, \sigma=2, \quad \gamma=.36$ \\
& Technology & $\alpha=.36, \delta=.025$ \\
& Productivity shocks & $a_{1}=.95, a_{2}=0$ \\
& & $\operatorname{var}\left(\varepsilon_{1}\right)=\operatorname{var}\left(\varepsilon_{2}\right)=.007^{2}, \operatorname{corr}\left(\varepsilon_{1}, \varepsilon_{2}\right)=.25$ \\
Sensitivity Experiments & Adjustment costs* & $\phi=.6$ \\
& High persistence & $a_{1}=.99, a_{2}=0$ \\
& High spillover & $a_{1}=.85, a_{2}=.15$ \\
& BKK & $a_{1}=.906, a_{2}=.088$ \\
\hline
\end{tabular}

*In the other sensitivity analysis experiments, the adjustment cost parameter in the bond economy is set to match the relative volatility of investment in the data. 
TABLE 2. Business cycle statistics: Baseline parameters

\begin{tabular}{|c|c|c|c|c|c|c|}
\hline \multirow[b]{3}{*}{ Statistic } & \multirow[b]{3}{*}{ Data } & \multicolumn{5}{|c|}{ Economy with } \\
\hline & & \multicolumn{3}{|c|}{ No Adjustment Costs } & \multicolumn{2}{|c|}{ Adjustment Costs } \\
\hline & & Complete Markets & Bond & Enforcement & Complete Markets & Bond \\
\hline \multicolumn{7}{|l|}{$\begin{array}{l}\text { Volatility } \\
\% \text { Standard deviations }\end{array}$} \\
\hline GDP & $\begin{array}{r}1.72 \\
(.20)\end{array}$ & 2.01 & 1.94 & 1.33 & 1.37 & 1.34 \\
\hline Net Exports/GDP & $\begin{array}{r}0.15 \\
(.01)\end{array}$ & 13.04 & 12.42 & 0.06 & 0.36 & 0.33 \\
\hline \multicolumn{7}{|l|}{ \% Standard deviations relative to GDP } \\
\hline Consumption & $\begin{array}{r}0.79 \\
(.05)\end{array}$ & 0.19 & 0.21 & 0.28 & 0.27 & 0.29 \\
\hline Investment & $\begin{array}{r}3.24 \\
(.17)\end{array}$ & 25.23 & 25.06 & 3.04 & 3.42 & 3.24 \\
\hline Employment & $\begin{array}{r}0.63 \\
(.04)\end{array}$ & 0.56 & 0.54 & 0.50 & 0.52 & 0.49 \\
\hline \multicolumn{7}{|l|}{$\begin{array}{l}\text { Domestic Comovement } \\
\text { Correlations with GDP }\end{array}$} \\
\hline Consumption & $\begin{array}{r}0.87 \\
(.03)\end{array}$ & 0.90 & 0.93 & 0.93 & 0.90 & 0.94 \\
\hline Investment & $\begin{array}{r}0.93 \\
(.02)\end{array}$ & 0.07 & 0.08 & 0.99 & 0.95 & 0.95 \\
\hline Employment & $\begin{array}{r}0.86 \\
(.03)\end{array}$ & 0.99 & 0.99 & 0.99 & 0.99 & 0.99 \\
\hline Net Exports/GDP & $\begin{array}{r}-0.36 \\
(.09)\end{array}$ & 0.06 & 0.06 & 0.27 & -0.02 & -0.05 \\
\hline \multicolumn{7}{|l|}{ International Correlations } \\
\hline Home and Foreign GDP & $\begin{array}{r}0.51 \\
(.13)\end{array}$ & -0.46 & -0.43 & 0.25 & 0.09 & 0.12 \\
\hline Home and Foreign Consumption & $\begin{array}{r}0.32 \\
(.17)\end{array}$ & 0.28 & 0.13 & 0.29 & 0.77 & 0.62 \\
\hline Home and Foreign Investment & $\begin{array}{r}0.29 \\
(.17)\end{array}$ & -0.99 & -0.99 & 0.33 & -0.17 & -0.09 \\
\hline Home and Foreign Employment & $\begin{array}{r}0.43 \\
(.11)\end{array}$ & -0.58 & -0.53 & 0.23 & -0.15 & -0.04 \\
\hline
\end{tabular}

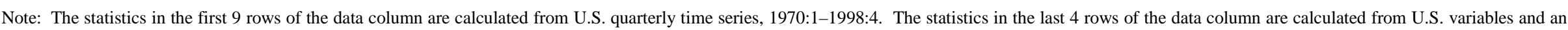

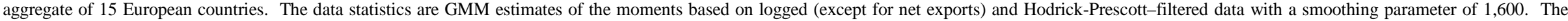
numbers in parentheses are standard errors. The model statistics are computed from a simulation of 100,000 periods, where the relevant series have been logged and HP-filtered as the data series.

Source: See Appendix. 
TABLE 3. Business cycle statistics: Sensitivity to technology shocks

\begin{tabular}{|c|c|c|c|c|c|c|c|c|c|}
\hline \multirow[b]{2}{*}{ Statistic } & \multirow[b]{2}{*}{ Data } & \multicolumn{4}{|c|}{ Enforcement Economy } & \multicolumn{4}{|c|}{ Bond Economy with Adjustment Costs } \\
\hline & & Baseline & $\begin{array}{c}\text { High } \\
\text { Persistence }\end{array}$ & $\begin{array}{c}\text { High } \\
\text { Spillover }\end{array}$ & BKK & Baseline & $\begin{array}{c}\text { High } \\
\text { Persistence }\end{array}$ & $\begin{array}{c}\text { High } \\
\text { Spillover }\end{array}$ & BKK \\
\hline \multicolumn{10}{|l|}{$\begin{array}{l}\text { Volatility } \\
\% \text { Standard deviations }\end{array}$} \\
\hline GDP & $\begin{array}{r}1.72 \\
(.20)\end{array}$ & 1.33 & 1.26 & 1.27 & 1.20 & 1.34 & 1.36 & 1.30 & 1.23 \\
\hline Net Exports/GDP & $\begin{array}{r}0.15 \\
(.01)\end{array}$ & 0.06 & 0.07 & 0.03 & 0.03 & 0.33 & 0.32 & 0.31 & 0.34 \\
\hline \multicolumn{10}{|l|}{$\%$ Standard deviations relative to GDP } \\
\hline Consumption & $\begin{array}{r}0.79 \\
(.05)\end{array}$ & 0.28 & 0.38 & 0.27 & 0.37 & 0.29 & 0.24 & 0.27 & 0.35 \\
\hline Investment & $\begin{array}{r}3.24 \\
(.17)\end{array}$ & 3.04 & 2.76 & 3.08 & 2.78 & 3.24 & 3.24 & 3.24 & 3.24 \\
\hline Employment & $\begin{array}{r}0.63 \\
(.04)\end{array}$ & 0.50 & 0.44 & 0.51 & 0.46 & 0.49 & 0.53 & 0.51 & 0.48 \\
\hline \multicolumn{10}{|l|}{$\begin{array}{l}\text { Domestic Comovement } \\
\text { Correlations with GDP }\end{array}$} \\
\hline Consumption & $\begin{array}{r}0.87 \\
(.03)\end{array}$ & 0.93 & 0.96 & 0.92 & 0.91 & 0.94 & 0.96 & 0.91 & 0.89 \\
\hline Investment & $\begin{array}{r}0.93 \\
(.02)\end{array}$ & 0.99 & 0.98 & 0.99 & 0.99 & 0.95 & 0.87 & 0.95 & 0.93 \\
\hline Employment & $\begin{array}{r}0.86 \\
(.03)\end{array}$ & 0.99 & 0.99 & 0.99 & 0.98 & 0.99 & 0.99 & 0.99 & 0.97 \\
\hline Net Exports/GDP & $\begin{array}{r}-0.36 \\
(.09)\end{array}$ & 0.27 & 0.25 & 0.42 & 0.52 & -0.05 & -0.34 & 0.07 & 0.02 \\
\hline \multicolumn{10}{|l|}{ International Correlations } \\
\hline Home and Foreign GDP & $\begin{array}{r}0.51 \\
(.13)\end{array}$ & 0.25 & 0.25 & 0.32 & 0.20 & 0.12 & 0.08 & 0.25 & 0.14 \\
\hline Home and Foreign Consumption & $\begin{array}{r}0.32 \\
(.17)\end{array}$ & 0.29 & 0.28 & 0.62 & 0.76 & 0.62 & 0.52 & 0.77 & 0.85 \\
\hline Home and Foreign Investment & $\begin{array}{r}0.29 \\
(.17)\end{array}$ & 0.33 & 0.33 & 0.35 & 0.08 & -0.09 & -0.51 & 0.08 & -0.30 \\
\hline Home and Foreign Employment & $\begin{array}{r}0.43 \\
(.11)\end{array}$ & 0.23 & 0.22 & 0.21 & -0.16 & -0.04 & -0.14 & 0.07 & -0.30 \\
\hline
\end{tabular}

Note: The statistics in the first 9 rows of the data column are calculated from U.S. quarterly time series, 1970:1-1998:4. The statistics in the last 4 rows of the data column are calculated from U.S. variables and an aggregate of 15 European countries. The data statistics are GMM estimates of the moments based on logged (except for net exports) and Hodrick-Prescott-filtered data with a smoothing parameter of 1,600. The numbers in parentheses are standard errors. The model statistics are computed from a simulation of 100,000 periods, where the relevant series have been logged and HP-filtered as the data series.

Source: See Appendix. 


\section{Figure 1. Productivity Shocks}

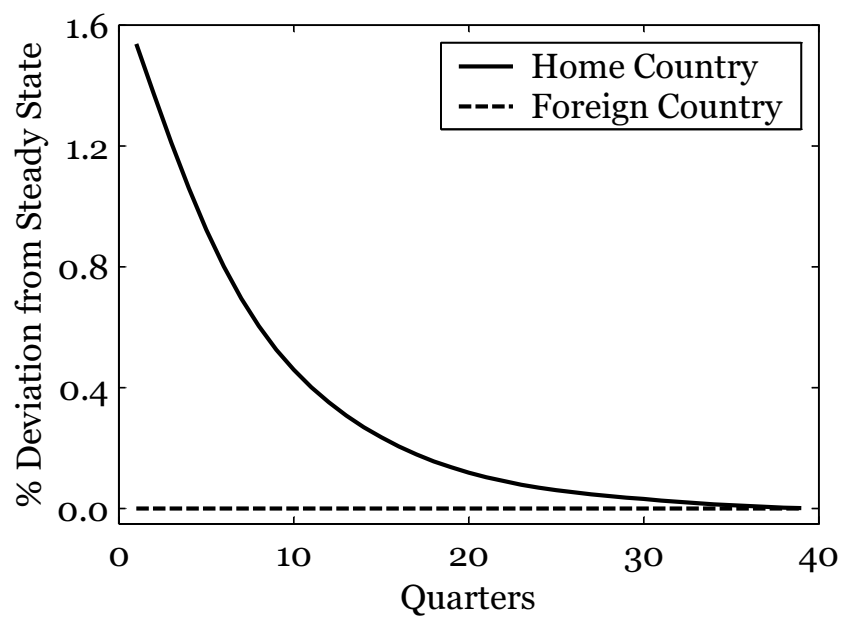


Figures 2-7. Impulse Responses to a Home Productivity Shock

\section{Output}

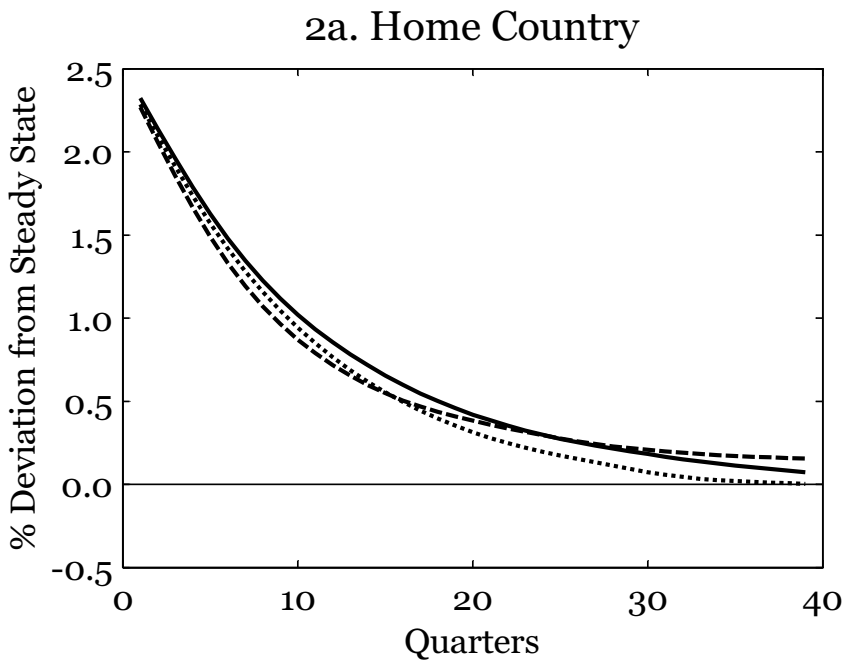

\section{Consumption}

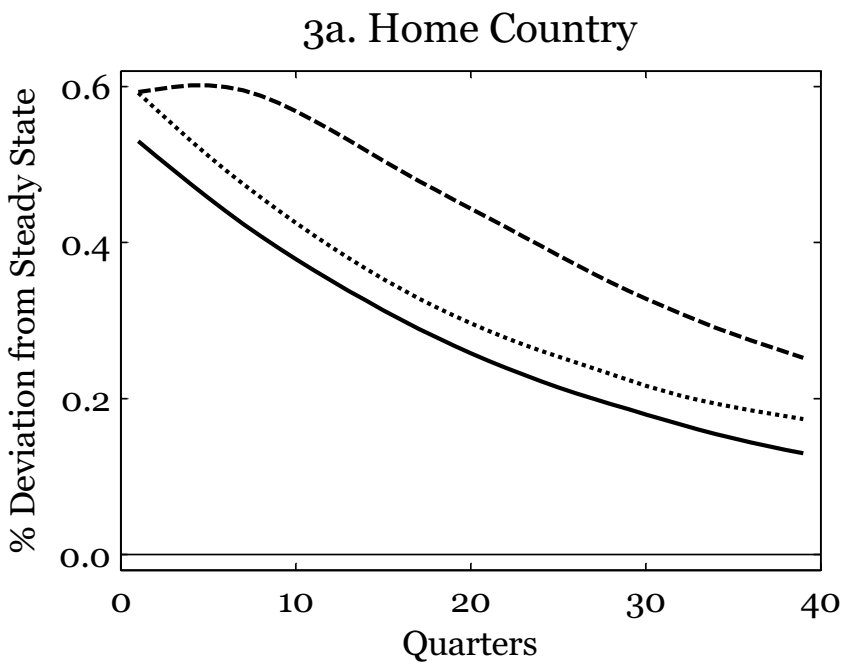

\section{Investment}

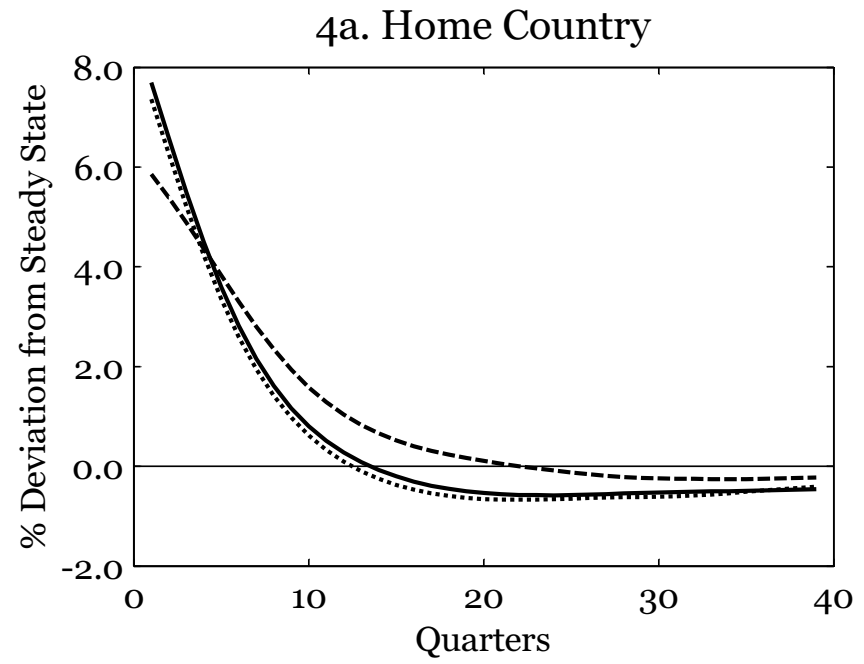

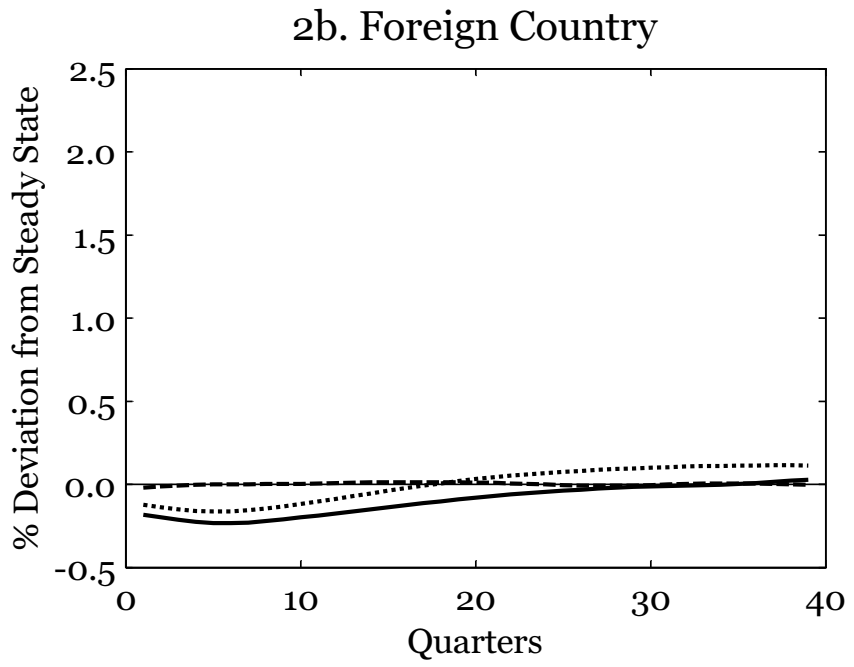

3b. Foreign Country

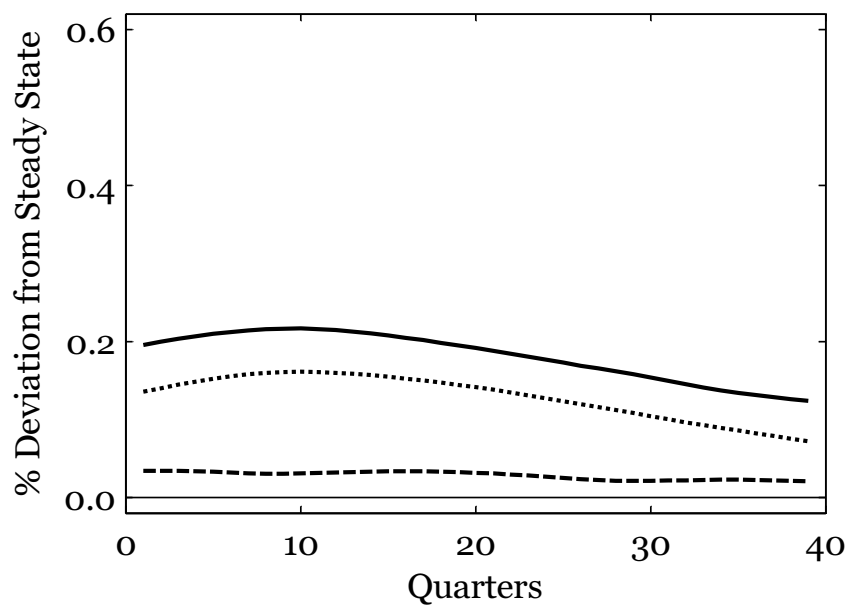

4b. Foreign Country

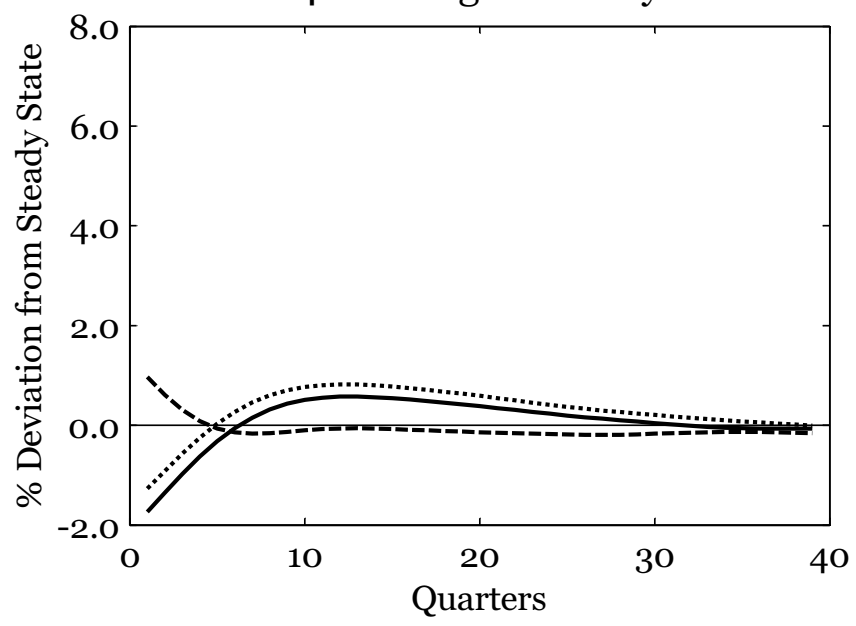




\section{Employment}
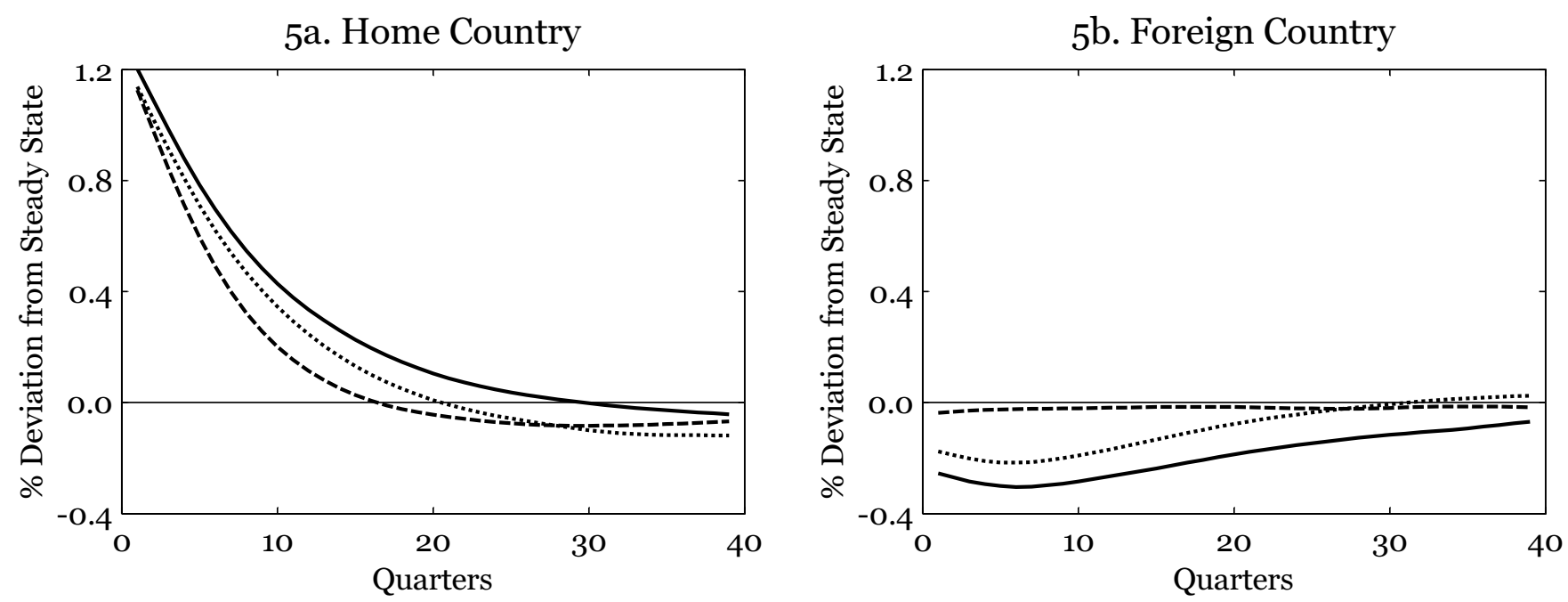

\section{Home Country Net Exports}

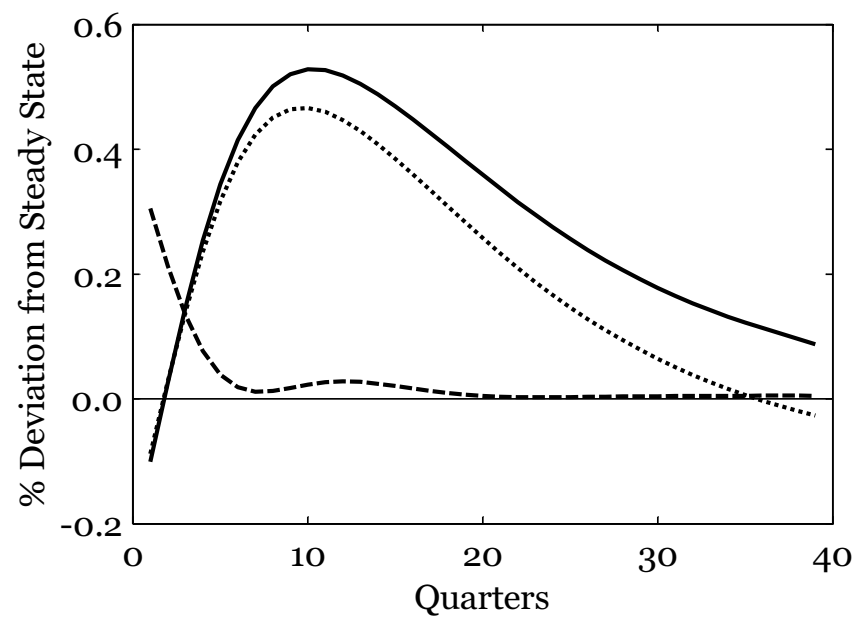

7. Foreign/Home Ratio of Marginal Utilities

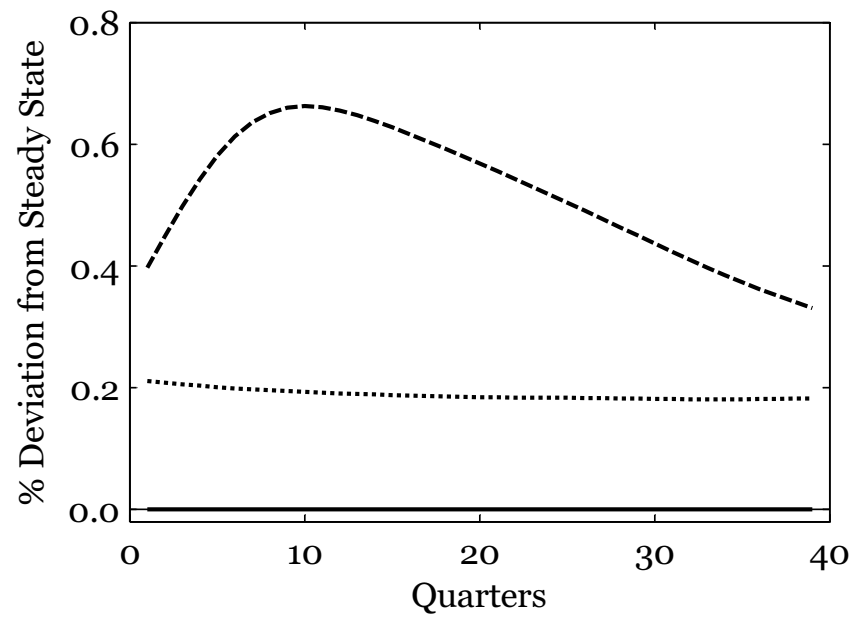

Complete markets

Bond

Enforcement 